\title{
Assessing the Learning Outcomes of Food-related Educational Tourism Events for University Students: The Case of the International Student Competition of Fermo, Italy
}

Sabrina Tomasi

(iD) https://orcid.org/0000-0002-7312-5360

Università di Macerata, Macerata, Italy

Department of Education, Cultural Heritage and Tourism e-mail: s.tomasi@unimc.it

\section{Alessio Cavicchi}

(iD) https://orcid.org/0000-0002-7793-865X

Università di Macerata, Macerata, Italy

Department of Education, Cultural Heritage and Tourism e-mail: a.cavicchi@unimc.it

\section{Gigliola Paviotti}

(iD) https://orcid.org/0000-0002-2609-4346

Università di Macerata, Macerata, Italy

Department of Education, Cultural Heritage and Tourism e-mail: gigliola.paviotti@unimc.it

Giovanna Bertella

(iD) https://orcid.org/0000-0001-5530-8588

UiT The Arctic University of Norway, Tromsø, Norway

School of Business and Economics

e-mail: giovanna.bertella@uit.no

Cristina Santini

(iD) https://orcid.org/0000-0002-6703-7823

Università Telematica San Raffaele, Rome, Italy

e-mail: cristina.santini@uniroma5.it 


\section{Abstract}

This paper examines the International Student Competition on Place Branding and Mediterranean Diet held in Fermo, Italy, in the context of the development of rural areas. This one-week food-related educational programme was organised by the University of Macerata's Department of Education, Cultural Heritage and Tourism in collaboration with The Piceno Laboratory on the Mediterranean Diet, a local network of public and private stakeholders committed to the promotion of Fermo area as a touristic destination based on traditional gastronomy. The aim of this study was to understand how and to what extent such food-related educational events may contribute to providing students with the knowledge, expertise and soft skills needed for careers in the food tourism sector. Of interest also was how such events may benefit the development of rural areas.

The ISC was founded in 2016 and continued in 2017, 2018 and 2019. In order to assess students' perceptions about the experience, specifically regarding what they felt they had learned about food tourism, and which soft skills they had acquired or honed, 13 students who participated in the 2017 event were interviewed for a qualitative study. Moreover, the authors drew upon information gleaned from interactions with students and teachers, as well as with several important actors of the local food and tourism sector, including tourism and hospitality entrepreneurs and representatives of government agencies, with whom they collaborated in the context of planning, running and evaluating the events. The findings show that the ISC can provide students with a good general understanding of the territory and practical knowledge about place branding and food tourism. In terms of career preparation, the combination of fieldwork activities with traditional lectures and group activities was particularly fruitful in promoting soft skills such as communication, efficient use of social media, teamwork, problemsolving and decision making.

Keywords: educational tourism, food tourism, experiential learning, knowledge, soft skills, employability. 


\section{Introduction}

In the Future of the Job Report, the World Economic Forum (WEF) argues that in the near future, some behavioural soft skills will replace or be more important than other technical and professional ones. For example, emotional intelligence, creativity and critical thinking are expected to play a fundamental role in enhancing future professional profiles (WEF). In defining the Student Employability Profile (Rees et al. 90-92) related to hospitality, the UK Higher Education Academy listed several skills and kinds of knowledge that a new graduate in this field should develop. Field-related skills include the ability to analyse and implement food, beverage and/or accommodation service systems, supported by ICT, mathematical and organisational skills. Important soft skills include interpersonal acumen as well as skills in communication and presentation, teamwork, critical thinking, and the ability to learn, especially from work experience.

The overall purpose of this study was to explore how and to what extent foodrelated educational events may contribute to providing students with the knowledge, expertise and soft skills needed for careers in the food tourism sector, thus improving their employability. The subject of this study was the International Student Competition on Place Branding and Mediterranean Diet held in Fermo, Italy, organised by the University of Macerata's Department of Education, Cultural Heritage and Tourism in collaboration with The Piceno Laboratory on the Mediterranean Diet, a local network of public and private stakeholders committed to the promotion of Fermo rural area as a touristic destination based on traditional gastronomy.

In Ritchie's description of an educational tourism experience, the learning component is a primary or secondary part of the journey. It can be related to the competencies that students develop during their studies to face the challenges of the world of work. In the food tourism literature and, in particular, in relation to the development of food tourism, various types of competencies have been identified as critically important (Bertella; Johanson et. al.; Rees et al.; Başaran). For example, Bertella identified scientific and local food knowledge, global and local managerial and political knowledge, and tourism knowledge.

The present article reports the results of a specific case study of a one-week educational program developed in line with the main ideas of the experiential learning approach (Dewey; Kolb), the International Student Competition (ISC) on Mediterranean Diet and Place Branding, organised by the University of Macerata (Italy) in the rural area of Fermo in collaboration with an association of government and private actors, The Piceno Lab on the Mediterranean Diet. During such a week, students attend talks, meet with local producers, visit farms, taste local products, participate in cooking lessons, and learn how to use social media to promote agritourism, a restaurant, a farm, a tour operator, or other such enterprises. 
In the competition, teams of students work on case studies to formulate sustainable, original and innovative action plans for one of these operators, in the overall context of promoting the rural development of the Marches Region.

The article is structured as follows: the first part provides a review of the background literature on educational tourism, with a specific focus on short-term study abroad programmes, experiential learning and soft skills for employability in relation with food tourism. Next, the background context of the educational event is described, and the applied methodology is explained. Finally, the collected data are analysed and discussed.

Students perceived that the experience of working on real cases in a multicultural context helped them gain useful knowledge and skills that would improve their employability. They pointed to such knowledge as a general understanding of the territory and practical information about place branding and food tourism. They felt that they improved their skills in communication, problem-solving and decision making, which, they said, could be adapted to other situations and workplaces as well.

\section{Theoretical background}

The case study of the International Student Competition of Fermo offers four interesting aspects for contemplation. The event in itself is an educational tourism experience that, through a competition, engages students in place and problem-specific experiential learning activities, in order to provide them with employability-related skills useful for their future; furthermore, it is a food tourism experience featuring the Mediterranean Diet, and involved students in promotion of the local food culture and lifestyle, and thus of the value of the area.

The following sections present a quick overview of the literature on Educational Tourism, Experiential learning, Food Tourism and Soft Skills for employability.

\section{Educational tourism}

Ritchie defines Educational Tourism as a "tourist activity undertaken by those who are undertaking an overnight vacation and those who are undertaking an excursion for whom education and learning is a primary or secondary part of their trip" (18), and indicates that it has several potential segments. In this study we consider the "education first" or purposeful segments which primarily serve to promote education and learning, for example, school excursions and exchange programmes, stays-abroad at language schools, and tourism related to university students. Stone and Petrick define study-abroad programs, including short-period programs, 
as touristic experiences perceived by the students as challenging and potentially enriching opportunities to travel, live and learn about another culture and language. Kalinowski and Weiler write that educational travel is motivated by curiosity to learn about other people, their language and culture, and by interest in stimulating cultural and naturalistic topics. For them, educational tourism goes "beyond a curiosity, interest or fascination for a particular topic. It involves a travel experience in which there is organised learning, whether that be formal or experimental" (Kalinowski and Weiler 17).

Educational tourism abroad offers a number of benefits: it provides students with an opportunity to learn about the political and social issues, the people, geography, history and culture of another country (Chieffo). It also can push them to improve their organisational, communication and problem-solving skills, and thus foster their personal growth (Gmelch).

\section{Experiential learning in tourism and hospitality degree programs}

Experiential activities, as described by Dewey, Boydell and Kolb, can play an important role in students' education, above all if set within specific learning programmes (Stone and Petrick). As Bauer and Bennett explain, field research projects are an important part of a degree program in tourism management because students can learn more about tourism in this setting than by attending lectures and seminars or reading textbooks and articles. Bauer and Bennett describe tourism as a multifaceted, multidisciplinary field, and argue that "hands-on" training that combines both theory and practice best prepares students for work in this complex arena. Similarly, Goh affirms that field trips in tourism education pique the interest of students, give them a better understanding of the specific subjects addressed in their program, and provide them with insights into future career pathways.

In this context, a well-rounded education is important: "tourism-related educational organizations should build a curriculum that combines culinary culture and tourism, enhances the cooperation between academia and industry, and deepens the knowledge and learning of culinary culture" (Horng and Tsai 812). In particular, gastronomic studies are multi-disciplinary, as they include history, sociology, literature, languages, nutrition, philosophy, hospitality and cooking, and may give direction in the planning process of communities and businesses (Scarpato). A wellrounded education is also facilitated by the combination of learning modalities. Travel and discovery provide an opportunity for students to reflect on their experiences, and this reflection is a vital part of learning (Mouton). In his research about experiential learning in tourism education in North Cyprus, Başaran (33) follows Kolb's theoretical framework and asserts that during work or training in the hospitality sector, students profit from their direct contact with stakeholders; reflective observation (RO) on the ideas they hear and situations they experience opens 
them to new perspectives. The opportunity to hear guest speakers such as business representatives and researchers, and engage in group discussions with them, enriches the learning experience as well. Of course, attending lectures and studying textbooks are important for the abstract conceptualisation (AC) of the subject. In addition, active experimentation (AE) through presentations, simulation games, role play, and practical workshops can be used effectively to support experiential learning.

Other modalities, such as location-based learning (Croy) and especially problem-based learning (Vygotsky; Paris) can be applied to business competitions, to help students enhance their employability by expanding their business knowledge, gaining work experience, and improving their abilities in problem-solving and teamwork; students also may find that these experiences boost their motivation and build up their self-esteem, and encourage them to engage in life-long learning. And, not unimportantly, these experiences can be fun (Shah et al.).

\section{Knowledge in food tourism}

Food is often an important aspect of rural tourism, as it allows the destination to express its own identity and allows tourists the opportunity to enjoy meaningful experiences, gaining in-depth knowledge about the local culture and cuisine (Bessière; Hjalager). Knowledge about food tourism is important for both tourists and tourism operators.

\section{Knowledge in food tourism from the tourists' perspective}

For tourists, food is a multifaceted cultural artefact to be enjoyed in many locations and through many activities such as food trails, events, festivals and visitor attractions (Everett and Aitchison). Hall and Sharples define food tourism as "visitation to primary and secondary food producers, food festivals, restaurants and specific locations" in order to experience a particular type of food or product of a specific region (10). Hall et al. consider food tourism as part of the local culture, "consumed" by tourists, an element of regional tourism promotion, a component of local agricultural and economic development, a key element to competitive destination marketing, an indicator of globalisation and localisation, and a product and service consumed by tourists with specific preferences and consumption patterns.

As Rinaldi argues, "food culture involves many different branding elements, including products (food and beverages), practices (eating and meals), the art and customs of preparing and eating (gastronomy), sensory elements (taste, smell, touch, visual), origins (organic food, ethical cuisine, locally produced food, etc.), preparation (ways of cooking), serving (fast food, slow food, street food, etc.) and the context in which food is served and consumed (restaurants, bars, markets, food 
quarters, streets, etc.)" (7). According to Horng and Tsai, in order to create a culinary tourism destination, it is necessary to identify the core resources and combine internal and external policies to support marketing strategies and to design products suitable to the target market, by creating a brand identity able to communicate the features and values of culinary tourism products. According to Richards, tourists want to increase their cultural capital and consider gastronomy as a creative experience rather than just consumption. In this sense, food tourism belongs to the creative tourism sector, and, therefore, specific knowledge and expertise are needed. Tourists are eager to learn about the ingredients used, the way they are grown, and how to cook them; they appreciate learning how culinary traditions have developed over time.

\section{Knowledge in food tourism from the perspectives of tourism operators and students}

Food tourism can influence the success of a destination in a competitive and rapidly changing tourism market. Local government assessors for tourism or rural development, tourism operators, local restaurants and hotels, as well as producers and sellers of local specialities must have the necessary food-related knowledge if they are to develop food tourism in their area. In addition, key elements for successful innovation and competition in this field are talent, knowledge retention and management skills (Hall et al.). Bertella analyses the role of knowledge in food tourism in agricultural and/or fishery areas and investigates several types of knowledge important for the development of food tourism in rural areas. These are:

- local food knowledge;

- scientific food knowledge;

- tourism knowledge;

- local managerial and political knowledge.

Food tourism can be boosted by the creation of networks among actors who detain different types of food knowledge in order to brand the destination.

In this context, education, training and research programmes may play an important role in regional development through food and tourism (Hall et al.). Specifically, hospitality education should include the study of gastronomy, in addition to management courses, to provide students with an understanding of the history, culture and traditions of the products and dishes of their own region or country (Santich). Furthermore, students should develop practical management skills, but also gain a general understanding of various social science disciplines, and become equipped to manage the economic, social and cultural impacts of tourism on the residents of the host region. 


\section{Soft skills for employability in the tourism sector}

The most accepted and shared definition of employability was articulated by Yorke and Knight who described it as "a set of achievements and skills, understandings and personal attributes helpful for graduates to gain employment and work successfully with a benefit for themselves, for the workforce, the community and the economy" (3). Soft skills are "desirable qualities for certain forms of employment that do not depend on acquired knowledge: they include common sense, the ability to deal with people, and a positive flexible attitude."1 For the purposes of this study, soft skills are understood here as personality-specific skills related to one's character, attitudes and behaviour; they are intangible, non-technical and their application is not limited to one's profession. In addition, they are constantly developed in everyday life and the workplace. Soft skills can be transferred from one context to another (UNESCO-IBE), but can be also technical, as is the case, for example, with fluency in languages or expertise with computers.

Even if a universal set of transferrable and soft skills has not been agreed upon (Caballero et al.), some helpful reference frameworks have been developed: the European Union identified 8 key competences for lifelong learning and several relevant soft skills, as have some other international government agencies (Crawford et al.; the U.S. Department of Education²; the Australian Department of Education; Bacigalupo et al.). These are summarized in Table 1.

Regarding employability in the hospitality sector, Baum called for curricula that develop skills in learning, communication, mathematics and IT, and teamwork, as well as competences in foods and beverages, and management. Similarly, Johanson et al. indicated as important competences the basic functional areas of management, such as the ability to recruit, train, and motivate; financial skills, communication skills, and customer care, computer-related skills, and knowledge about workplace security and safety. They also included specific knowledge related to food preparation, such as ingredients, sauces and stocks, and basic culinary production processes.

As Ruhanen's case study showed, experiential approaches are useful learning tools for improving the employability of tourism and hospitality students. They can contribute to bridging the gap between academic knowledge and the required practical knowledge and skills those in the workforce should have. They promote learning, interest and enthusiasm for the subject, work experience and industry practice. Lee reports that industry-based experiential learning enhanced the learning outcomes of hospitality students: it increased their understanding of how organisations work, helped them view their career expectations more realistically,

1 https://www.collinsdictionary.com/dictionary/english/soft-skills (Accessed 30 Sep 2019)

2 https://cte.ed.gov/initiatives/employability-skills-framework (Accessed 30 Sep 2019) 
Assessing the Learning Outcomes of Food-related Educational Tourism Events...

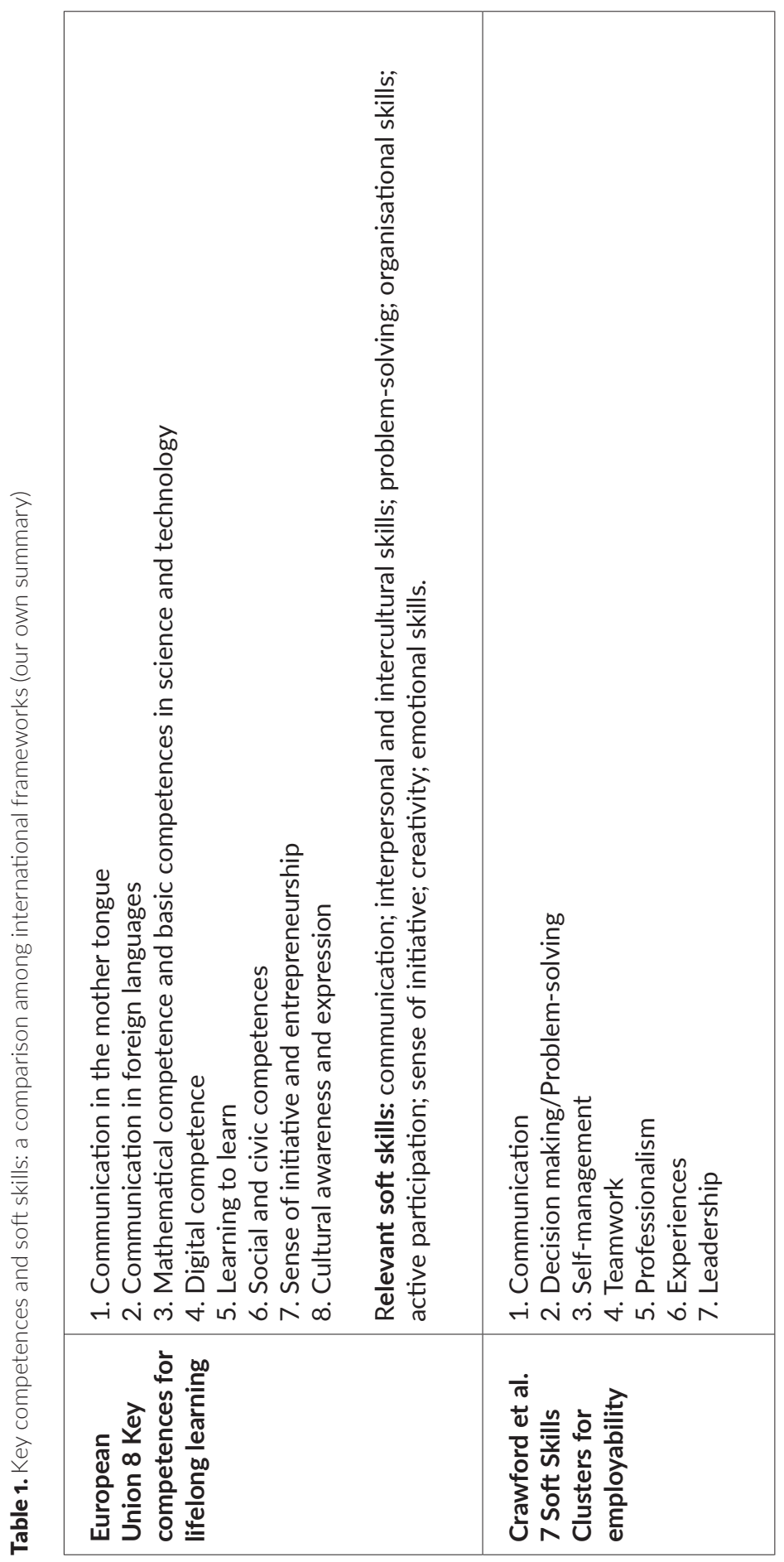




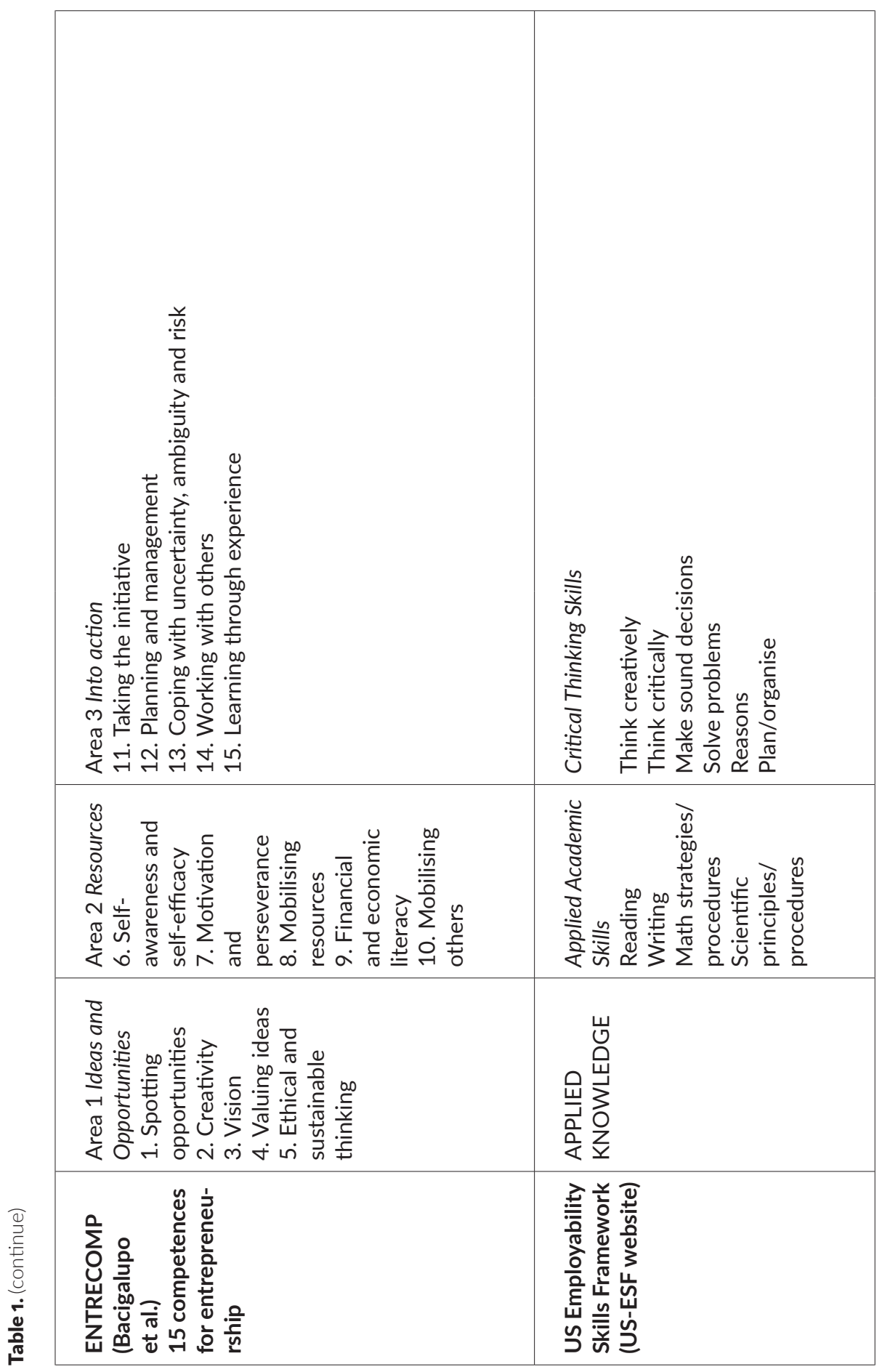


Assessing the Learning Outcomes of Food-related Educational Tourism Events...

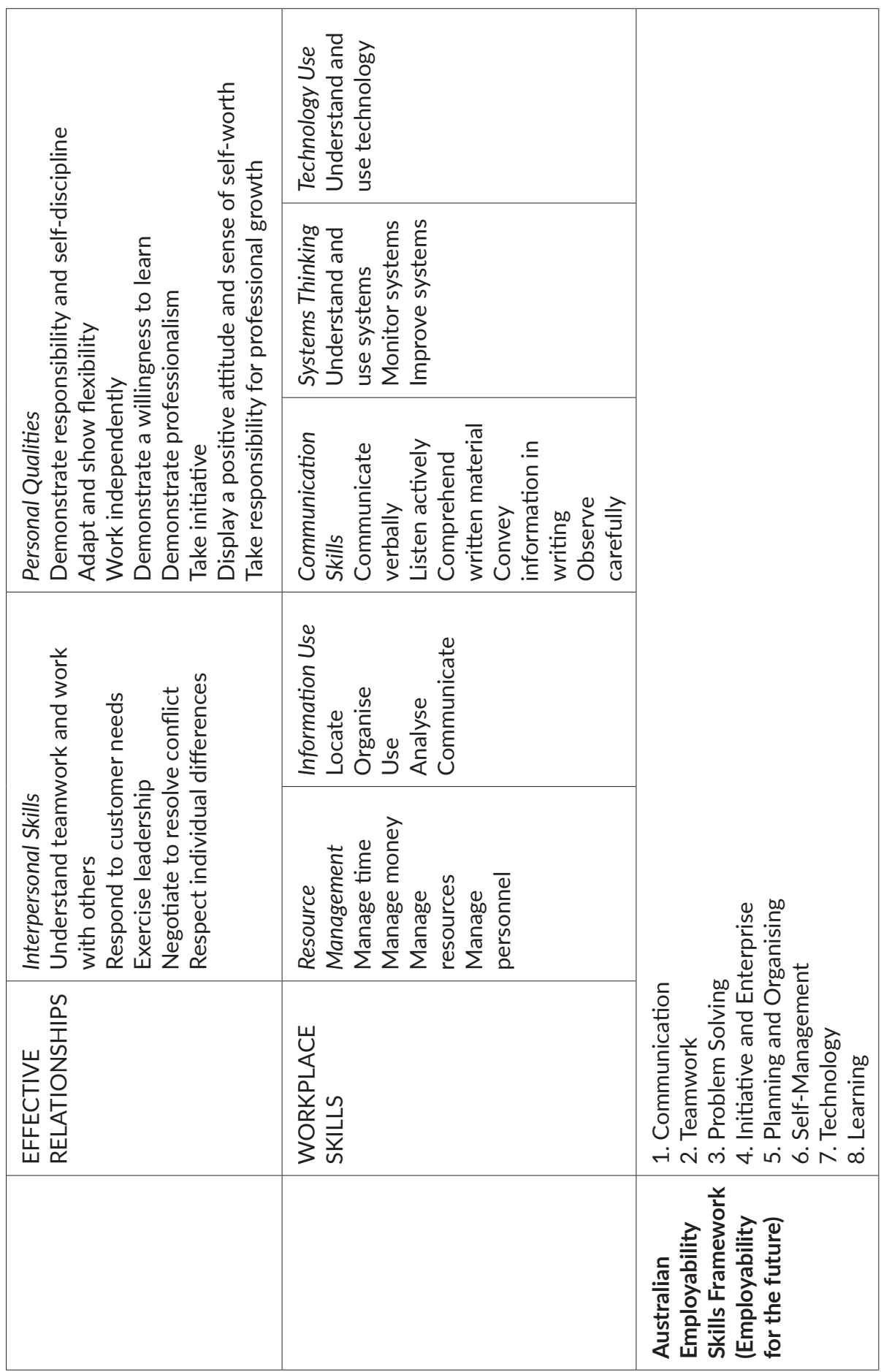


developed their network of professional contacts, spurred their ability to take initiative, increased their ability to adapt to change, honed their leadership skills, and boosted their financial management skills. According to García-Rosell, in order to work in and improve the tourism industry, tourism students should develop knowledge and competencies through problem-based learning (PBL) activities that stimulate critical approaches and reflexibility. Students should live and experience tourism and hospitality work rather than simply acquiring knowledge about it. Problem-based learning in tourism education allows students to develop skills like teamwork, creativity, problem-solving and leadership and helps them in developing the flexibility and adaptability needed to respond to the socio-technological changes affecting the tourism and hospitality industry.

\section{Background context: The International Student Competition on Place Branding and the Mediterranean Diet}

The week-long International Student Competition of Fermo (ISC) is a study-abroad programme based on the Mediterranean Diet brand. Established in 2016 by the Department of Education, Cultural Heritage and Tourism of the University of Macerata, in collaboration with The Piceno Laboratory on the Mediterranean Diet, a local network of public and private stakeholders committed to promoting the Fermo area as a touristic destination based on traditional gastronomy, it has attracted students from Italy and abroad every year since 2016 (http://www.laboratoriodietamediterranea.it/it/international-student-competition-2019).

The small rural hill town of Montegiorgio, near Fermo, 30 kilometres from the Adriatic Sea, was chosen to host the ISC because of its particular importance as a representative of the traditional Mediterranean diet and its link to longevity. In fact, since the town was marked by a high number of centenarians, and its traditional cuisine typical of the Mediterranean diet, a cohort of men from Montegiorgio was one of the sixteen enrolled in the long-term Seven Countries Study, conducted from 1958 to 1999, which compared data on heart and vascular disease with information on traditional eating patterns and lifestyles in the seven participating countries (USA, Finland, Italy, the Netherlands, Yugoslavia, Greece, and Japan). ${ }^{3}$ Exploiting this claim to fame, local leaders chose to brand the Fermo area as the land of Mediterranean Diet in efforts to promote food tourism here. The Piceno Laboratory of the Mediterranean Diet played an important intermediary role among the local actors, linking the touristic offer to food, health and wellness, and

3 http://www.sevencountriesstudy.com/ (Accessed 30 Sep 2019) 
engaging the support of the University of Macerata. One of the outcomes of this collaboration was the ISC, with the following objectives:

- for students: discovering connections between gastronomy, events and place branding; understanding the potential of food and gastronomy for sustainable development; developing skills for destination management challenges; understanding the potential of Information and Communications Technology (ICT) for place branding activities; discovering Italian culture, lifestyle and gastronomy,

- for stakeholders and local actors: elaborating innovation and development paths to increase the international reputation of the destination, through an ICT-based real-time marketing of the territory (Cavicchi et al.).

The participants came from universities in Italy, Norway, Belgium, Poland, Ukraine, the Czech Republic, belonged to different nationalities, and had diverse educational backgrounds (Tourism and Hospitality Management, Economics and Business Management, Agricultural Studies). They attended seminars about Food \& Wine Tourism led by researchers from Italy and abroad, set in ancient theatres and locations symbolic of the local cultural heritage. In addition, they attended cooking classes, visited local farms and had field trips, met local producers and gained insights into food processes, local gastronomy traditions and culture. Participants were hosted in rural B\&Bs and farmhouses, to offer them the opportunity to learn about local hospitality and become familiar with the landscape and its attractions.

The students worked in groups in close collaboration with local stakeholders to give them the opportunity to engage in real case studies. The participants in the first ISC in 2016 were asked to come up with an innovative idea to help the Piceno Laboratory of Mediterranean Diet elaborate a promotional strategy for the Fermo area using the Mediterranean Diet as a brand. The next year, participants were given two different assignments: 1) the application of the Business Model Canvas (Osterwalder and Pigneur) to two local firms, in order to implement promotional strategies based on their distinctive resources; and 2) the integration of the identified strategies within a sustainable tourism development plan for the area. In 2018, again, participants worked to elaborate a promotional strategy for the Fermo area using the Mediterranean Diet as a brand and in 2019, participants were asked to provide local stakeholders with a promotional video representing the characteristics of a gastronomic tourism experience in Fermo area.

Each year, students also helped promote the Fermo area by acting as "ambassadors," in a daily social media competition, sharing pictures and contents using official hashtags, the impact of which was then analysed by staff at the Polytechnic University of the Marche in Ancona. Each day, the participant who had the greatest social media impact won a prize consisting of local products. In doing all these activities, students "translated" theoretical ideas and tools into concrete plans for 
the local destination. Local students supported international students in the activities with local stakeholders. "Translation" also took a literal form, with Italian participants helping foreign participants communicate with local stakeholders.

\section{Methodology}

In order to investigate the learning outcomes of the ISC and, more specifically, what kind of knowledge and skills students might have developed through this experience, this study relied on the three data sources: first, a general questionnaire about motivation for participating, expectations for the event, and level of satisfaction with the event, administered to all the 2016 participants and some of the 2017 participants; second, follow up interviews with 13 of the 2017 students about knowledge gained and skills improved through the event; and third, information gleaned by the authors in the context of their various roles in planning, organising and running the ISC, during numerous informal conversations with students, teachers, tourism and hospitality entrepreneurs, and representatives of government agencies.

\section{A preliminary assessment of the ISC experience}

The goal of the first phase was to assess the motivations, expectations, and level of satisfaction of the students who participated in the ISC. They were asked to fill out a questionnaire organised on a 5-point Likert-type scale, by assigning values to affirmations such as "I wanted to meet other students interested in tourism," "I expected excellent lectures," "I feel that I have gained a good understanding of the job of local entrepreneurs/producers," "My participation in this competition is an important part of my total university experience," and "My satisfaction as a learning experience." Comparison among the means revealed that the Italian students appeared to be more interested in and satisfied with the learning experience related to food tourism, local traditions and culture than their colleagues from universities abroad. In fact, the majority of the respondents were students of the University of Macerata's Master's Program in International Tourism Destination Management, which includes the ISC as part of the second year of studies. They were familiar with the subjects addressed during the event, which were relevant to their education and preparation for future employment. On the basis of the questionnaire results, it was decided that a second phase should be undertaken, specifically with the University of Macerata students who had participated in the 2017 ISC, to gain more information about the outcomes in terms of knowledge and skills development. 


\section{Semi-structured interviews on learning outcomes of the ISC}

The second phase employed a qualitative approach in which 13 open-ended questions were asked of 7 young women and 6 young men, five from abroad ( 2 from India, 2 from Ghana, 1 from Russia), and the rest from Italy ( 3 from the Marche Region, 1 from Latium, 2 from Campania, 1 from Apulia, 1 from Sicily). Most of the 30-minutes interviews were conducted via Skype. Since the interviewer had participated in the ISC and knew the respondents personally, the interviews had an open and friendly tone and were marked by mutual trust. The students who could not Skype submitted their answers by email. The contents of the interview were elaborated following the frameworks of Bertella; and Crawford et al. because they allow synthesising the characteristics of the other frameworks. Table 2 shows the soft skills clusters and related characteristics according to Crawford et al.

As mentioned in the literature review section, Bertella identified important kinds of knowledge in food tourism in agricultural and/or fishery areas: local and scientific food knowledge, tourism knowledge, and local and global managerial and political knowledge. Many scholars (Horng and Tsai; Baum; Johanson et al.; Lee; Scarpato; Richards; Hjalager; Hall et al.; Santich) confirmed the importance of these competences, seen as essential in the perspective of regional branding and development of sustainable food tourism strategies.

The interview was divided into different sections, as in the following Table 3.

The interviews were recorded and transcribed, and content analysis based on theoretically derived codes was conducted.

\section{Action research}

Following an action research approach (Gilmore and Carson) the authors involved in different roles in the planning, organisation and training at the ISC, through their direct experience and conversations with the students and local stakeholders had the opportunity to collect data. A participant observation approach (Jorgensen) was applied, to note and interpret the physical and social context and the interactions among the participants.

\section{Findings}

The data collected showed that most of the students had little previous knowledge about the Fermo area and its local gastronomy and food tourism. Only those who had an educational background related to tourism management were more aware of these topics, mainly students from the Marche Region, who also had a broader knowledge of the area and the local gastronomy. 
Sabrina Tomasi, Alessio Cavicchi, Gigliola Paviotti, Giovanna Bertella, Cristina Santini

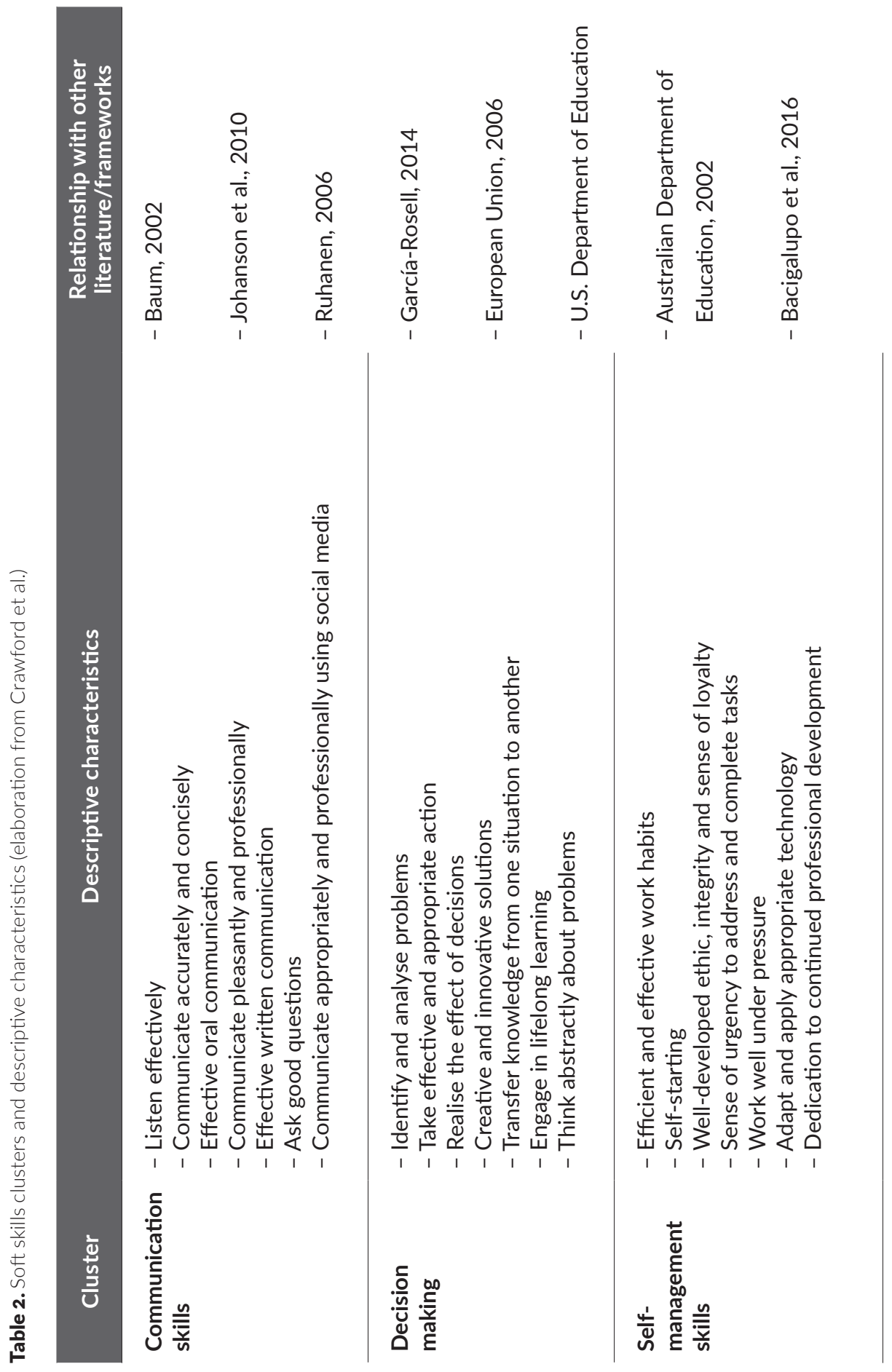


Assessing the Learning Outcomes of Food-related Educational Tourism Events...

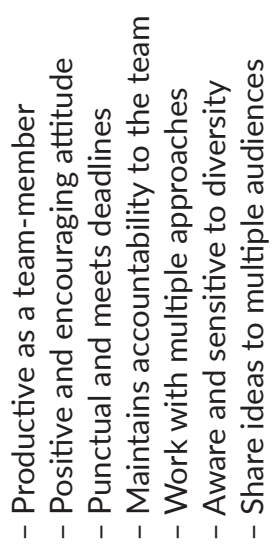

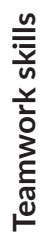

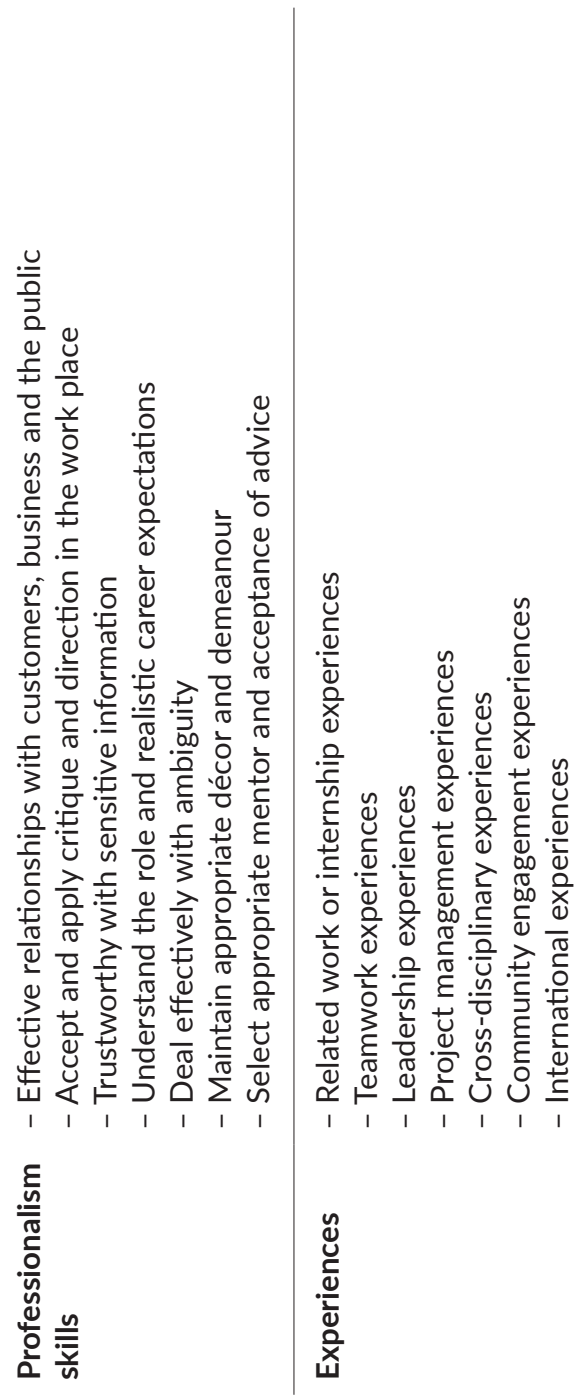

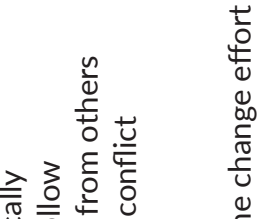

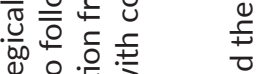

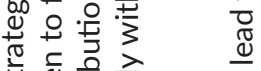
离㐫产 兰艺起器

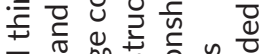
뭉

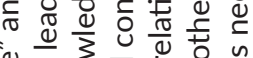
"थ

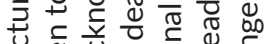

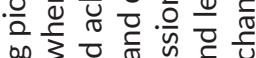

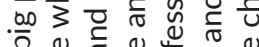

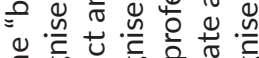

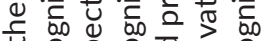
웡 원을 눙

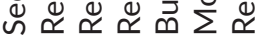

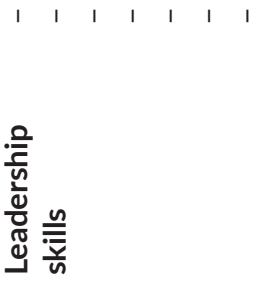




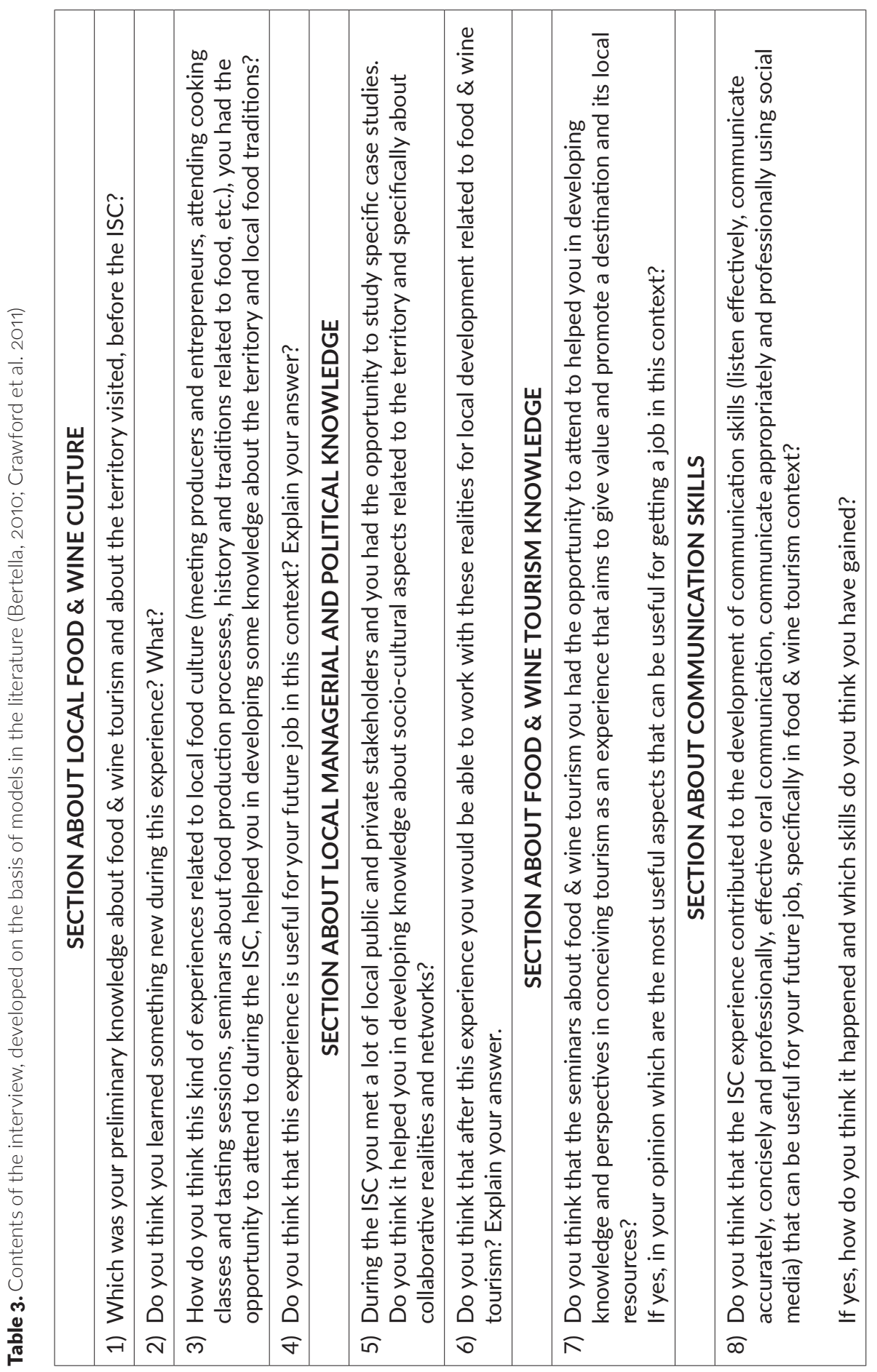


Assessing the Learning Outcomes of Food-related Educational Tourism Events...

\begin{tabular}{|c|c|c|c|c|c|c|c|c|c|}
\hline 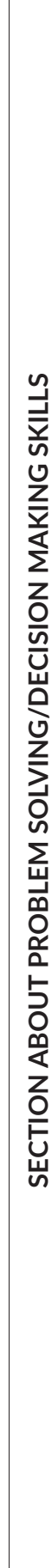 & 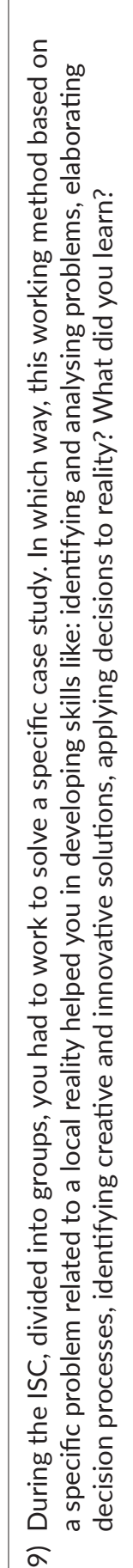 & 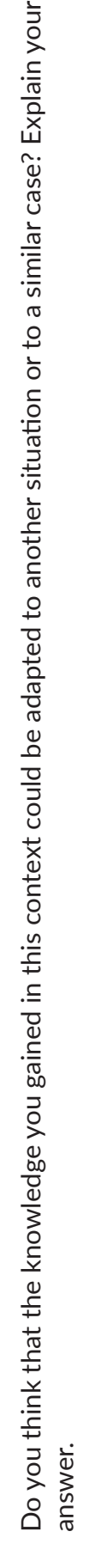 & 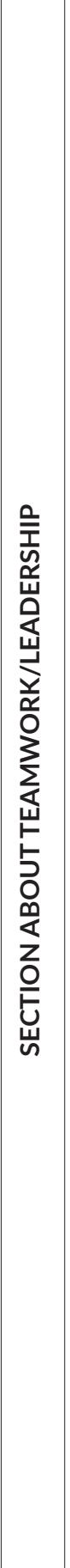 & 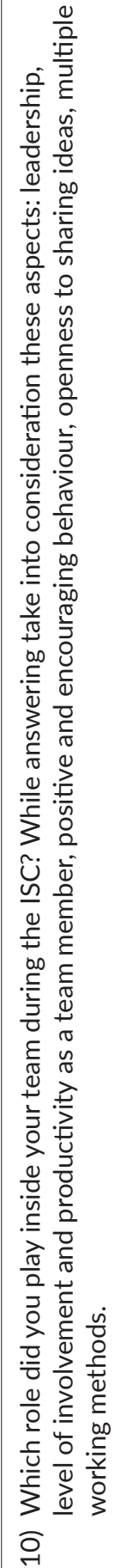 & 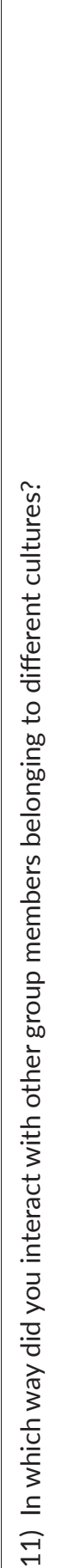 & 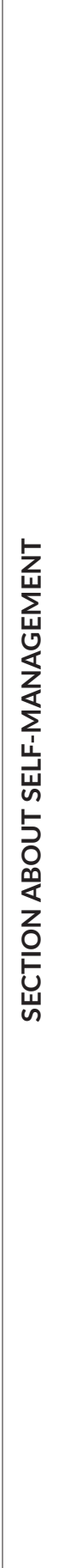 & 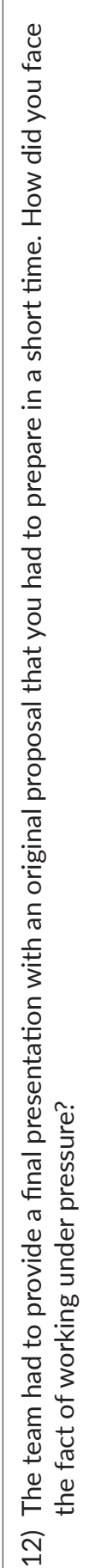 & 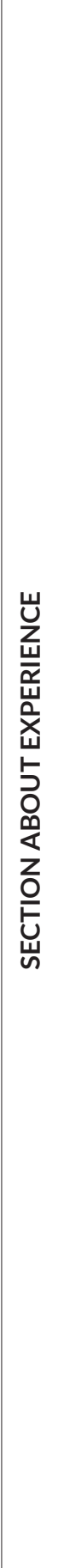 & 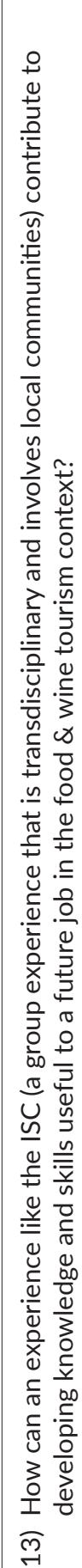 \\
\hline
\end{tabular}




\section{Knowledge and soft skills acquired during the ISC experience}

Respondents deemed that the ISC experience had helped them gain knowledge and develop soft skills through direct contact with the local context and dialogue with local stakeholders, as well as through the seminars and the experiential learning activities held. Some themes emerged from the interviews.

\section{Understanding of the area}

More generally, students affirmed that during the ISC they learned about local food \& wine, local management and politics, and food tourism.

The most evident aspect was the acquisition of a general understanding of the area in terms of:

- in-depth knowledge about local food production and local, small food-related firms,

- awareness about the relationship between the land and food authenticity,

- the importance of considering food as a resource for local development (above all, after the 2016 earthquakes which hit the area),

- potential future work opportunities for students in the food tourism field in that area.

Two indicative statements were:

"I had the opportunity to meet large and small local businesses, to learn first-hand about their potential, their weaknesses and their unique features".

"The ISC allowed me to explore the untouched beauty of the Fermo territory and to taste the local food, and experience the richness of the Mediterranean Diet."

By achieving a more complete understanding of the area, participants could understand the specific context, analyse problems and needs, gain awareness about the objectives of the Piceno Laboratory on Mediterranean Diet, get closer to local businesses and understand how to plan promotional initiatives to brand them. The respondents could observe the commitment of local producers to guarantee quality products, see their passion for their jobs, and recognise the importance of local food for tourism.

The seminars on food tourism held by professors from different countries and the experiential learning activities (meetings with producers and entrepreneurs, cooking classes and tasting sessions, seminars about food production processes, history and traditions related to food, etc.), supported students in improving their 
knowledge of the local context. However, they need to pursue further knowledge about the fundamentals of food tourism, to be better equipped to promote local development through food tourism.

\section{The dialogue with local stakeholders as a means for knowledge acquisition}

Most respondents said they developed their knowledge about the territory and local food traditions through direct connection with local stakeholders. Through meetings and farm visits, they gained awareness of the context in which people work, the issues they face, the way they try to market themselves, and the processes implemented to create quality products, whether they were small family-owned firms or SMEs that also worked as "ambassadors" of area. One of the respondents said that he understood why local people were passionate about and proud of their traditions and felt they should express these sentiments in their promotional activities.

Students also highlighted how this experience supported them in acquiring knowledge about the local socio-cultural structure and networking:

It was a great experience to meet the stakeholders; it helped us understand how the tourism industry works, especially throughout the territory. It gave me a clear picture of the practical network of the significant stakeholders.

\section{Experiential learning as a means for knowledge acquisition}

The acquisition of knowledge about the territory and local food traditions was also related to the learning methods proposed during the ISC, such as experiential learning and problem-based learning, including field visits, cooking lessons, workshops, and teamwork activities.

Seminars were helpful, but experiential learning activities appeared to be more effective in the students' learning, as they provided first-hand experiences involving all the participants' senses, as indicated in these observations:

[...] talking to producers, taking part in cooking classes and tasting the delicious local cuisine got me to live Le Marche region as I could have never done otherwise...;

Apparently, the best way to learn something is to experience it, see, touch and taste it. It's a much more effective way of learning than reading theory, so ISC gave me a very profound and practical insight about local food and wine culture and cooking and sharing food traditions. 


\section{Seminars as a means for learning about food tourism and developing soft skills}

Respondents indicated that the seminars held by international professors helped them gain technical knowledge about place branding and food tourism. Just like a puzzle, some said, this kind of activity provided all the pieces to have a complete overview of the food tourism topic related to the territory investigated. In their opinion, the main competition was a useful way to build upon the theoretical foundation through a hands-on approach; they also valued the aspect of working in teams to develop a real case study for the local area. Marketing, the use of social media as a promotional tool, and gastronomy as a brand and a tourism driver were considered the most interesting topics.

Yes, the Place Branding, Cultural Heritage Management courses and the International Seminars gave me a quite comprehensive overview of what a tourist product should be. It was certainly useful because it helped me gain a new perspective and made me learn about innovative and unusual approaches, mainly presented during the seminars that week.

Students felt that they improved their ability to listen as well as their skills in public speaking during the seminars. Some of them appreciated the technical knowledge gained and the food tourism-related terminology learned throughout the event, which they could later use in their final presentations. The seminar about the use of social media for promotional aims was particularly appreciated. It helped hone the participants' communication skills in terms of effective and professional communication.

\section{Networking as a means for soft skills acquisition}

During the week, the students had the opportunity for networking with local stakeholders, their team members, the other participants, and their professors. They perceived to have gained several soft skills, especially through the dialogue with local stakeholders and through teamwork. An overview of these skills is provided in Table 4. 
Assessing the Learning Outcomes of Food-related Educational Tourism Events...

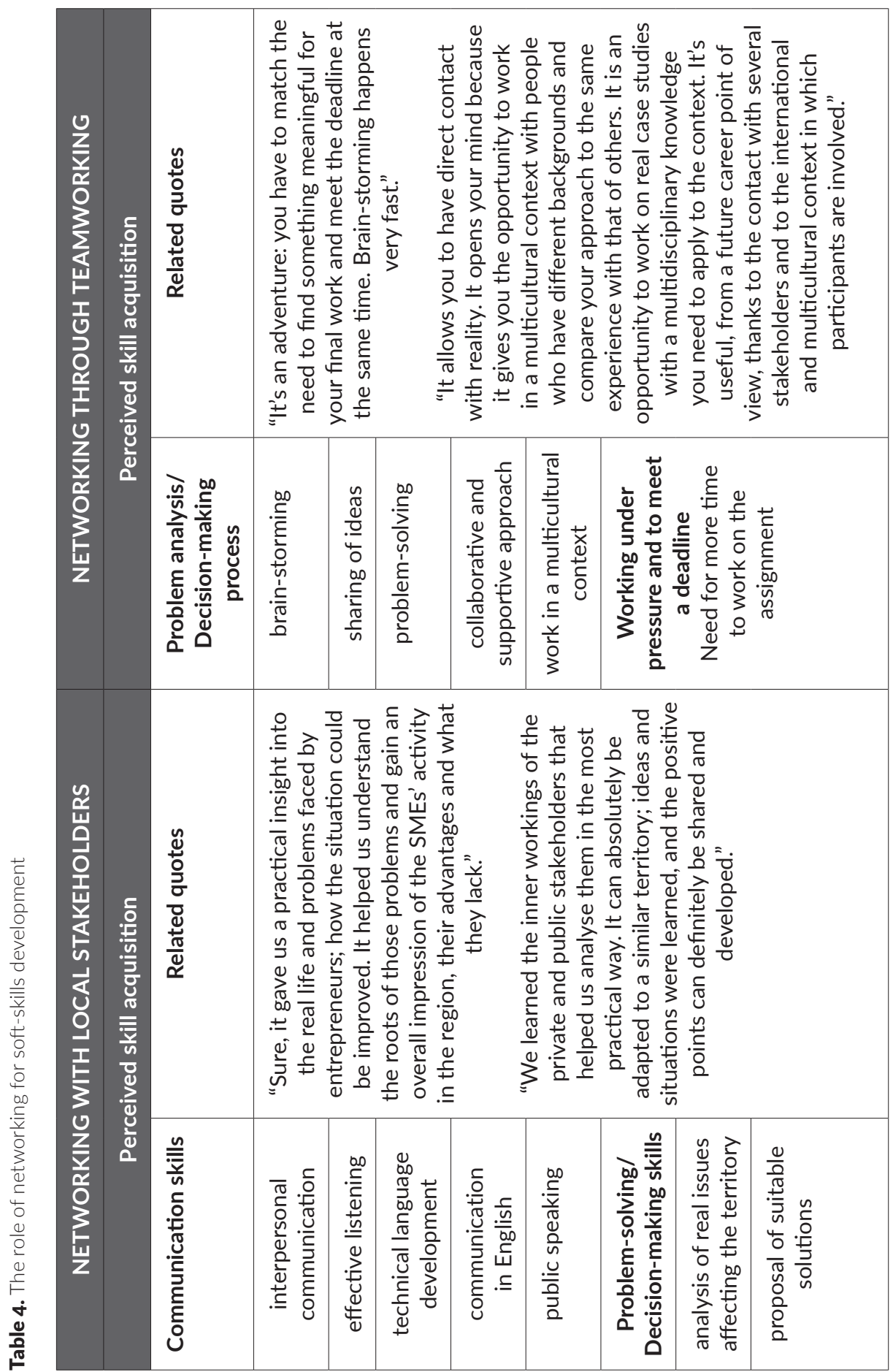




\section{Discussion}

The findings of this study suggest that educational tourism experiences based on experiential learning and problem-based learning approaches (Dewey; Boydell; Kolb; Vygotsky; Paris) enable students to gain employability skills, business knowledge and work experience (Shah et al.). During the ISC, students learned about critical approaches and the reflexibility useful in the tourism industry, through the application of problem-based learning (García-Rosell). In line with Stone and Petrick, the ISC can be therefore defined as a short study-abroad programme as well as an educational touristic experience. Students had opportunities for personal and professional growth through travel, experience, learning about the gastronomic culture of the Fermo area and its efforts to promote food tourism, and also enhanced their fluency in English, the official language of the event.

With regard to employability, students perceived to have gained:

1. Understanding of the territory: the dialogue with local stakeholders and the experiential learning activities offered students an overview of the socio-cultural and economic processes regulating the territory. Local networks embody local managerial and political knowledge and play a role in providing quality and coherence to the services and products offered (Bertella). These experiences may help students to start working at a local level for local development and place branding by identifying challenges and needs and by finding innovative and feasible solutions. However, they also acknowledged they might need to improve their knowledge about place branding and food tourism management.

2. Practical knowledge about local food, place branding and food tourism: according to Bertella, food-related knowledge is one of the most important assets to promote and give value to a destination, and food tourism is a key element for destination development, local promotion and the valorisation of local resources. Technical knowledge about place branding and food tourism is essential to regional development in the food and tourism area, according to Hall et al. One of the main characteristics of the ISC is to link theoretical knowledge about place branding and food tourism to the practical experience gained through the experiential learning activities proposed. Participants gained practical insight into the field by attending seminars, visiting farms, sharing information with local stakeholders, and taking part in cooking classes and tasting sessions. This was also highlighted by the students during the conversations with the authors. During the presentations of the final projects on the last day of the competition, the authors observed that the teams of students applied the knowledge acquired to a suitable proposal for the firms involved through the use of the tools provided (business model canvas).

3. Soft skills for employability. Students gave particular importance to the following soft skills: 
a) communication skills; the students noted that during the ISC experience, they improved their skills in listening and speaking effectively, formulating good questions and communicating appropriately and professionally using social media. In particular, all week the students communicated and interacted with people to whom they may not usually relate, such as students and professors from other countries, local farmers and business people, and government functionaries, for example. Similarly, the teams presented their final project to a heterogeneous audience.

b) problem-solving and decision-making skills: the dialogue with local stakeholders and the brainstorming with the other members of the team helped the students develop some of the abilities involved in decision-making (Crawford), namely, identifying and analysing problems; transferring knowledge from one situation to another; proposing creative and innovative solutions; taking effective and appropriate action; and assessing the effect of a solution. The multicultural context of the mixed teams contributed to the development of several points of view useful for interpreting different situations and increasing the shared knowledge. Furthermore, all respondents said that it was possible to adapt the solutions they found to other contexts by applying several tools presented during the ISC. The problem-based learning approach showed them specific issues affecting the Fermo area. Rural areas often share similar problems and need similar solutions, which nonetheless need to be adjusted to each case.

c) self-management and teamwork skills: students noted that working well under pressure (self-management) was a challenge but also a limitation and felt they would have benefitted from more time to do the final project (Crawford et al.). Self-management also has to do with efficient and effective work habits and a sense of urgency to complete tasks. These aspects had to be extended to the whole team, as the competition was based on teamwork. Regarding the characteristics of teamwork skills (Crawford et al.), students particularly highlighted their positive and encouraging attitudes and their productive approaches as well as the sensitivity to diversity, as the teams were multicultural.

Even if the respondents did not explicitly name them, some other skills related to the experience (Crawford et al.) emerged from the interviews: project management experiences; cross-disciplinary experiences; community engagement experiences; international experiences. Similarly, students highlighted some of the leadership and professionalism skills outlined by the author. During the teamwork activity they practised skills related to respect for others and acknowledgement of their contributions, as well as dealing constructively with conflicts, a key aspect of leadership. The authors present at the event observed that student networking with local stakeholders and professors led to effective relationships with "customers, business and the public." Similarly, students practised behaviour appropriate 
to the settings, accepted advice, gained greater understanding of their own role and refined their career expectations to be more realistic, all of which are professionalism skills.

While the ISC seems to have contributed to the students' knowledge and soft skills development, the findings showed the need for follow-up activities that can bring together local stakeholders and students in order to expand the knowledge and experience gained during the ISC.

\section{Conclusions}

This study explored how and to what extent food-related educational events may contribute to providing students with the knowledge, expertise and soft skills needed for employability in the food tourism careers. It focused on student experiences at the week-long ISC event, arranged by the University of Macerata (Italy), an educational programme that facilitated the co-creation of food tourism knowledge by bringing together local stakeholders and students. Students worked at a local level to accomplish their competition assignment and learn about the reality of the Fermo area, gaining an understanding of the context in which they would have to intervene. They perceived to have developed useful skills and knowledge for employability through their work on real cases in a multicultural context. Locals benefitted from the students' competition projects, which offered creative contributions for promotional activities and place branding that could be implemented to promote tourism in the area.

Having participated in all the planned activities, the students felt they had gained a general understanding of the territory and practical knowledge about place branding and food tourism; in addition, they thought they had improved their soft skills in communication, problem-solving and decision-making, all of which are useful for enhancing their employability. They valued the opportunity to exchange knowledge, share ideas and work in a multicultural environment. All these learning outcomes can be adapted to other situations and can be useful in the workplace.

On the basis of student questionnaires and interviews, as well as conversations with local stakeholders, it emerged that the ISC event offers students a good opportunity to gain sector-related knowledge and skills. More in general, this kind of event linking academics and local stakeholders, education and tourism, and experiential and formal learning has potential for both students and people working for local development.

Even so, a need was noted for further follow-up events, to provide more experience and theoretical knowledge. More opportunities could be created to work at the local level, strengthening the connection between students and local 
stakeholders, perhaps through internships and students-led initiatives at the local level.

Some limitations also emerged from the study. First, the interviews were conducted only with 13 University of Macerata students of the 2017 ISC. Further research including the students from the other universities abroad could provide a broader perspective. Moreover, while the authors gleaned interesting input from the stakeholders during informal conversations, future, more structured work to encompass their perspective could prove useful. Finally, further research could be conducted to assess what or how much the local stakeholders learned, and whether the ISC provides a beneficial setting for knowledge exchange that can foster successful place branding and enhance the development of local food tourism.

\section{Conflict of interest statement}

Even though three of the authors work for one of the institutions that manages the event presented in this case study (one University of Macerata professors and two UNIMC doctoral students), they declare that there is no conflict of interest.

\section{Works Cited}

Australian Department of Education, Science and Training, Australian Chamber of Commerce and Industry \& Business Council of Australia. Employability Skills for the Future. Canberra: Department of Education, Science and Training, 2002.

Bacigalupo, M., et al. EntreComp: The Entrepreneurship Competence Framework. Luxembourg: Publication Office of the European Union, 2016.

Başaran, K. Experiential Learning in Tourism Education in the North Cyprus. Academic dissertation, 2016.

Bauer, K. W., and J. S. Bennett. "Alumni Perceptions Used to Assess Undergraduate Research Experience." The Journal of Higher Education 74.2 (2003): 210-230.

Baum, T. "Skills and Training for the Hospitality Sector: A Review of Issues." Journal of Vocational Education and Training 54.3 (2002): 343-364.

Bertella, G. "Knowledge in Food Tourism: The Case of Lofoten and Maremma Toscana." Current Issues in Tourism 14.4 (2011): 355-371.

Bessière, J. "Local Development and Heritage: Traditional Food and Cuisine as Tourist Attractions in Rural Areas." Sociologia Ruralis 38.1 (1998): 21-34.

Boydell, T. Experiential Learning. Manchester: Department of Adult Education, University of Manchester, 1976. 
Caballero, C. L., et al. "The Work Readiness Scale (WRS): Developing a Measure to Assess Work Readiness in College Graduates." Journal of Teaching and Learning for Graduate Employability 2.2 (2011): 41-54.

Cavicchi, A., et al. "Higher Education Institutions as Managers of Wicked Problems: Place Branding and Rural Development in Marche Region, Italy." International Food and Agribusiness Management Review, 16(A) (2013): 51-68.

Cavicchi, A., et al. "Participatory Location-based Learning and ICT as Tools to Increase International Reputation of a Wellbeing Destination in Rural Areas: A Case Study." Tourism, Health, Wellbeing and Protected Areas. Eds. I. Azara, et al. Wallingford: CABI, 2018, pp. 82-94.

Chieffo, L. "The Freshman Factor: Outcomes of Short-Term Education Abroad Programs on First-Year Students." Conference Poster and Presentation at NAFSA Conference. Minneapolis, MN, May, 2007.

Crawford, P., et al. Comparative Analysis of Soft Skills: What is Important for New Graduates. Michigan State University and the University Industry Consortium, 2011, pp. 1-24.

Croy, W. G. "Location-based Learning: Considerations for Developing and Implementing Destination-partnered Authentic-experiential Learning." Journal of Hospitality \& Tourism Education 21.1 (2009): 17-23.

Dewey, J. Experience and Education. New York: Macmillan, 1938.

Everett, S., and C. Aitchison. "The Role of Food Tourism in Sustaining Regional Identity: A Case Study of Cornwall, South West England." Journal of Sustainable Tourism, 16.2 (2008): 150-167.

García-Rosell, J. C. "Promoting Critical Reflexivity in Tourism and Hospitality Education through Problem-based Learning." The Routledge Handbook of Tourism and Hospitality Education. Eds. D. Dredge, and M. J. Gross. New York and London: Routledge, 2014, pp. 279-291.

Gilmore, A., and D. Carson. 'Integrative' Qualitative Methods in a Services Context.” Marketing Intelligence \& Planning 14.6 (1996): 21-26.

Gmelch, G. "Crossing Cultures: Student Travel and Personal Development." International Journal of Intercultural Relations 21.4 (1997): 475-490.

Goh, E. "The Value and Benefits of Fieldtrips in Tourism and Hospitality Education." Higher Learning Research Communications 1.1 (2011): 60-70.

Hall, C. M., et al. "Consuming Places: The Role of Food, Wine and Tourism in Regional Development." Food Tourism around the World. Eds. M. C. Hall, et al. New York and London: Routledge, 2004, pp. 37-71.

Hall, C. M., and L. Sharples. "The Consumption of Experiences or the Experience of Consumption? An Introduction to the Tourism of Taste." Food Tourism around the World. Eds. M. C. Hall, et al. New York and London: Routledge, 2004, pp. 13-36. 
Hjalager, A. M. "A Typology of Gastronomy Tourism." Tourism and Gastronomy. Ed. A. M. Hjalager and G. Richards. New York and London: Routledge, 2002, pp. 21-35.

Hjalager, A. M. "What Do Tourists Eat and Why? Towards a Sociology of Gastronomy and Tourism." Gastronomy and Tourism. Eds. J. Collen and G. Richards, Gravenwezel/Schilde, Belgium: Academie Voor de Streekgebonden Gastronomie, 2003, pp. 54-74.

Horng, J. S., and C. T. Tsai. "Constructing Indicators of Culinary Tourism Strategy: An Application of Resource-based Theory." Journal of Travel \& Tourism Marketing 29.8 (2012): 796-816.

http://www.ibe.unesco.org/fileadmin/user_upload/Publications/IBE_ GlossaryCurriculumTerminology2013_eng.pdf. Accessed 9 Oct 2019.

Johanson, M., et al. "Revealing Key Competencies of Hospitality Graduates Demanded by Industry: A 25-year Review." 2010. International CHRIE Conference-Refereed Track. 5. https://scholarworks.umass.edu/refereed/CHRIE_2010/Saturday/5

Jorgensen, D. L. "Participant Observation." Emerging Trends in the Social and Behavioral Sciences: An Interdisciplinary, Searchable, and Linkable Resource, Wiley Online Library (2015): 1-15.

Kalinowski, K. M., and B. Weiler. "Educational Travel." Special Interest Tourism. Eds.

B. Weiler and C.M. Hall. London: Belhaven Press, 1992, pp. 15-26.

Kolb, D. A. Experiential Learning. Englewood Cliffs, NJ: Prentice Hall, 1984.

Lee, S. A. "Increasing Student Learning: A Comparison of Students' Perceptions of Learning in the Classroom Environment and Their Industry-based Experiential Learning Assignments." Journal of Teaching in Travel \& Tourism 7.4 (2008): 37-54. Mouton, W. "Experiential Learning in Travel Environments as a Key Factor in Adult Learning." Delta Kappa Gamma Bulletin 69.1 (2002): 36-42.

Osterwalder, A., and Y. Pigneur. Creare modelli di business. Milano: FAG, 2012.

Paris, C. M. "Social Constructivism and Tourism Education." Journal of Hospitality, Leisure, Sport and Tourism Education 10.2 (2011): 103-108.

Rees, C., et al. The Student Employability Profile. A Guide for Higher Education Practitioners. UK Higher Education Academy, 2006.

Richards, G. "Gastronomy: An Essential Ingredient in Tourism Production and Consumption." Tourism and Gastronomy. Ed. A. M. Hjalager and G. Richards. New York and London: Routledge, 2002, pp. 2-20.

Rinaldi, C. "Food and Gastronomy for Sustainable Place Development: A Multidisciplinary Analysis of Different Theoretical Approaches." Sustainability 9.10 (2017): 1748.

Rinaldi, C., and A. Cavicchi. "Universities' Emerging Roles to Co-create Sustainable Innovation Paths: Some Evidences from the Marche Region." AESTIMUM 69 (Dicembre 2016): 211-224. 
Ritchie, B., et al. Managing Educational Tourism, Clevedon: Channel View Publications, 2003.

Robles, M. M. "Executive Perceptions of the Top 10 Soft Skills Needed in Today's Workplace.” Business Communication Quarterly 75.4 (2012): 453-465.

Ruhanen, L. "Bridging the Divide between Theory and Practice: Experiential Learning Approaches for Tourism and Hospitality Management Education." Journal of Teaching in Travel \& Tourism 5.4 (2006): 33-51.

Santich, B. "The Study of Gastronomy and Its Relevance to Hospitality Education and Training." International Journal of Hospitality Management 23.1 (2004): 15-24.

Scarpato, R. "Gastronomy as a Tourist Product: The Perspective of Gastronomy Studies." Tourism and Gastronomy. Ed. A. M. Hjalager and G. Richards. New York and London: Routledge, 2002, pp. 51-70.

Shah, S., et al. "Use of Business Competitions to Enhance Student Employability in Higher Education". Recent Advances in Educational Technologies: Proceedings of the 2015 International Conference on Education and Modern Educational Technologies (EMET 2015). Educational Technologies Series, 18. Greece: WSEAS, 2015, pp. 140-147.

Stone M. J., and J. F. Petrick. "The Educational Benefits of Travel Experiences: A Literature Review." Journal of Travel Research 20.10 (2013): 1-14.

The Seven Countries Study. http://www.sevencountriesstudy.com/ Accessed 23 Mar 2017.

U.S. Department of Education, Employability Skills. http://cte.ed.gov/initiatives/ employability-skills-framework Accessed 14 Jan 2018.

UNESCO International Bureau of Education IBE Glossary of Curriculum Terminology, UNESCO, Geneva, Switzerland, 2013.

Vygotsky, L. S. Mind in Society: The Development of Higher Psychological Processes. Cambridge, MA: Harvard University Press, 1978.

World Economic Forum. The Future of Jobs Employment, Skills and Workforce Strategy for the Fourth Industrial Revolution. Jan 2016. http://www3.weforum.org/ docs/WEF_Future_of_Jobs.pdf. Accessed 14 Jan 2018.

Yorke, M., and P. T. Knight. Learning \& Employability. Embedding Employability into the Curriculum. The Higher Education Academy, 2004, pp. 1-28.

Sabrina Tomasi - Doctoral candidate in Human Sciences at the Department of Education, Cultural Heritage and Tourism at the University of Macerata (Italy). Her main fields of interest and research are: Educational Tourism, Ecotourism, Health Tourism and Experiential Tourism. She is involved in EU research projects (The Wine Lab and FoodBiz) about the role of higher education institutions 
in promoting bottom-up approaches and stakeholder engagement to facilitate innovation and co-creation in rural areas.

Alessio Cavicchi - Associate Professor at the Department of Education, Cultural Heritage and Tourism at University of Macerata (Italy). His main fields of interest and research are consumer food choice, economics of food quality and safety, sustainable tourism and innovation in the agro-food sector. He has experience as coordinator of several EU funded projects, and as an invited expert for several programmes and DGs of the European Commission in the food sector (DG Agri, DG Research, DG Regio-Urbact, Joint Research Center, European Agency for Competitiveness and Innovation).

Gigliola Paviotti - Doctoral candidate in Education at the University of Macerata. Her research interests include employability, transitions from education to work, and engagement of universities for regional development. She is currently involved in research projects related to pedagogy for employability and co-creation approaches for employment and entrepreneurship purposes.

Giovanna Bertella - Associate Professor at the School of Business and Economics, UiT The Arctic University of Norway, Tromsø. Her research interests include: 1) Tourism and leisure studies; 2) Food \& beverages studies (food consumption/ production from an animal ethics perspective, rural entrepreneurship); 3) Futures studies. The theoretical perspectives adopted in her studies are: Management (knowledge and collaboration), Marketing (experiential marketing, consumer culture theory), Entrepreneurship/Innovation (practice-based and institutional theory).

Cristina Santini - Associate Professor at Università Telematica San Raffaele, Rome (Italy). Her research interests include: food and wine business; entrepreneurship and ecopreneurship and strategic management. She is interested in research methodology and more specifically in case study, participatory approaches and action research. 